\title{
An Aircraft Pallet Damage Monitoring Method Based on Damage Subarea Identification and Probability-Based Diagnostic Imaging
}

\author{
Bin Liu, ${ }^{1,2}$ Tingzhang Liu (D), ${ }^{1}$ Yue Lin, ${ }^{1}$ and Jianfei Zhao ${ }^{1}$ \\ ${ }^{1}$ School of Mechatronic Engineering and Automation, Shanghai University, Shanghai 200444, China \\ ${ }^{2}$ Department of Military Supply and Fuel, Air Force Logistics College, Xuzhou 221000, China \\ Correspondence should be addressed to Tingzhang Liu; liutzhcom@163.com
}

Received 9 April 2019; Accepted 13 August 2019; Published 7 November 2019

Academic Editor: Juan C. Cano

Copyright $\odot 2019$ Bin Liu et al. This is an open access article distributed under the Creative Commons Attribution License, which permits unrestricted use, distribution, and reproduction in any medium, provided the original work is properly cited.

\begin{abstract}
To improve the safety and economy of aircraft pallet use, an aircraft pallet damage monitoring method based on damage subarea identification and probability-based diagnostic imaging is proposed. In the proposed method, first, the large aircraft pallet monitoring area is divided into rectangular subareas, and a piezoelectric transducer sensor is pasted on each vertex of the rectangular subarea that is used to excitation and sensing the Lamb wave. Second, the damage subarea is identified according to the diagonal damage indexes. Third, the damage position in the damage subarea is calculated using the probability-based diagnostic imaging method and coordinate probability weighted algorithm. Finally, the aircraft pallet damage can be localized based on the damage subarea position. Frequency selection and damage simulation study results show that the Lamb wave is sensitive to aircraft pallet damage whose centre frequency ranges from $50 \mathrm{kHz}$ to $150 \mathrm{kHz}$, and the damage index of a steel ball is less than that of all real aircraft pallet damage from $95 \mathrm{kHz}$ to $125 \mathrm{kHz}$. The verification results show that the proposed method can locate aircraft pallet damage with an error of less than $2 \mathrm{~cm}$.
\end{abstract}

\section{Introduction}

An aircraft pallet is a unit load device used to load luggage, freight, mail and other things onto an aircraft, as shown in Figure 1. The use of a pallet enables a large quantity of cargo to be bundled into a single unit. This process leads to fewer loads, which means savings in ground crew time and effort as well as the prevention of flight delays [1]. With the rapid development of air transportation, the aircraft pallet has become an important piece of air transport support equipment that has been increasingly widely used. The aircraft pallet will be subjected to various complex structural deformations in the states of fork loading, rolling, hoisting and compression during use, which can easily lead to various damages, such as adhesive failure. The strength and deflection of the aircraft pallets will be reduced in the damaged state, which seriously threatens the safety of the cargo, aircraft and personnel. Therefore, the aircraft pallets need to return to the factory to be fully overhauled using nondestructive testing methods after three years of use. However, some pallets still have acceptable performance, resulting in great waste. Additionally, some pallets are frequently used or subjected to violent loading, resulting in serious structural damage. Therefore, it is necessary to study the structural damage monitoring technology of aircraft pallets to improve their safety and economy of use.

Structural health monitoring (SHM) technique uses permanently installed sensor for online inspection of the overall health status of the structure, which can improve the safety and reliability of structures, reduce maintenance costs, avoid failures and provide failure warnings [3, 4]. Among the various technologies explored for SHM, the Lamb wave has shown great potential because it is sensitive to various damages over long distances $[5,6]$. In most applications, the Lamb wave is generated and received by piezoelectric transducer sensor distributed on the test specimen $[7,8]$. Piezoelectric transducers made of Lead Zirconate Titanate is small size, high sensitivity and broad dynamic range, which can be used as either actuators or sensors due to their piezoelectric effect and vice versa [9-11]. The SHM technology based on Lamb wave and piezoelectric transducer is an efficient SHM method, more and more researchers apply it to large area monitoring, active and passive monitoring, small damages monitoring and online 

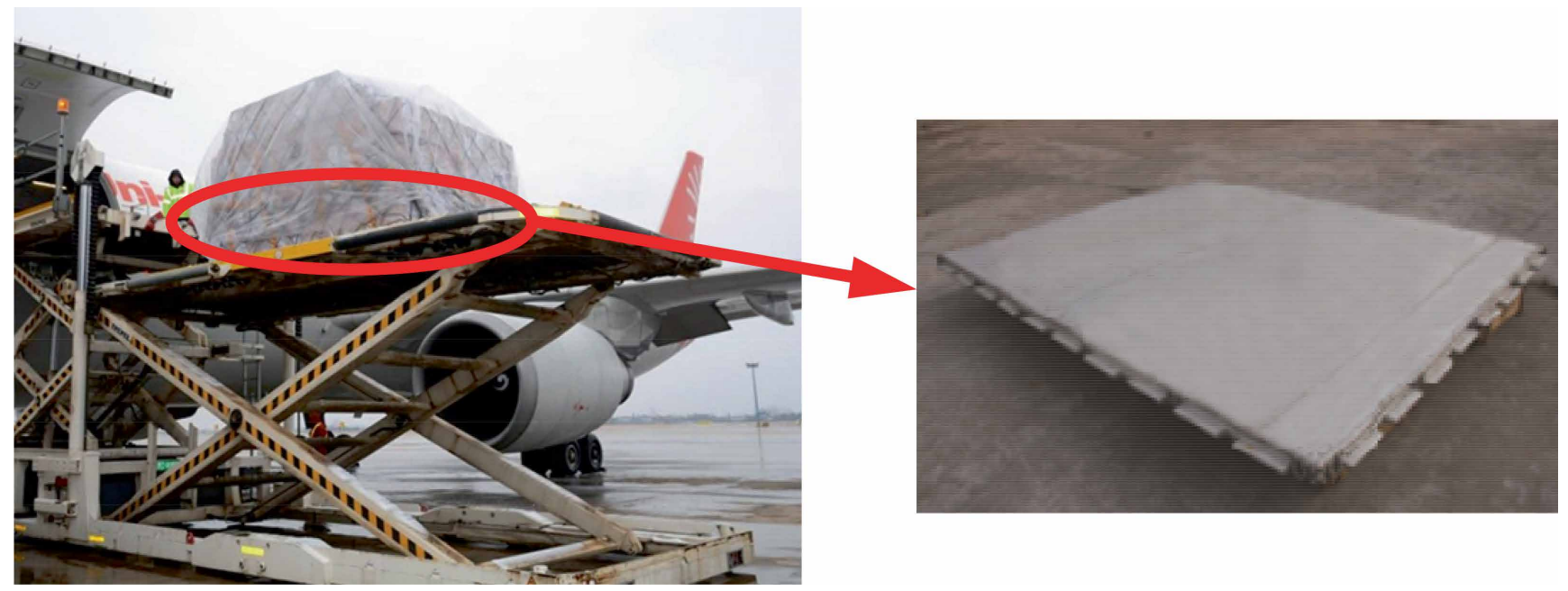

Figure 1: The aircraft pallet [2].

monitoring [12-14]. Qing et al. overview of piezoelectric transducer based SHM technology developed for aircraft applications in the past two decades [15]. Song et al. developed an embedded piezoceramic smart aggregate for health monitoring of concrete structures, and realized the concrete pile damages, the grouting quality of concrete-filled steel tubes, the debonding damage of FRP bar reinforced concrete, corrosion-induced degradation detected [16-22]. Roy et al. developed a load and temperature compensation model for ultrasonic guided waves based SHM using piezoelectric transducers accounting for the changes in both the phase-shifts and signal amplitude [23].

Among the existing researches of SHM technology based on Lamb wave and piezoelectric transducer, damage imaging algorithm is an easily interpretable and intuitive image reflecting the overall health status of the monitored structure, which has been widely studied $[24,25]$, such as the delay-and-sum imaging method [26-30], ultrasonic phased array imaging method [31-34], time reversal imaging method [35-39], multiple signal classification method [40-43] and spatial-wavenumber filter imaging method [44-47]. Lu et al. improved the delay-and-sum imaging method by employing the Boolean ADD operation instead of the addition or the multiplication operation, and used reflection coefficient, local maximum value based envelop-detection method, additional time shift to cancel the artifacts and increase the efficient and accuracy of defect detection [48]. Yu et al. combine ultrasonic phased array imaging method and spatial-wavenumber filter to detect and quantify impact induced delamination damage in composites, which is reduced the total composite inspection time by $97 \%$ compared to the full scanning laser Doppler vibrometer approach $[49,50]$. Zhu et al. studied the time reversal imaging method in frequency-wavenumber domain for multiple damage imaging, which is about two orders of magnitude faster than that in the time domain [51]. The present studies show that these methods require knowledge of the Lamb wave velocity in the damage location. An aircraft pallet is made of corrosion-resistant aluminum with a soft wood or fiberglass core and is framed on all sides by aluminum rails; its structural characteristics will change during use. The anisotropy of the aircraft pallet will be highlighted by the complex structure and structural characteristic changes, which makes it difficult to accurately obtain the Lamb wave velocity.

The probability-based diagnostic imaging method is a fast and simple damage imaging method that does not use the Lamb wave velocity $[3,52]$. The damage index of each path in the pitch-catch sensor network is used in this method. The effective influence area of each path damage index is determined by the elliptical trajectory method. Then, the structural damage probability image can be obtained by aggregating each actuator-sensor path's probability image. The position with the highest damage probability is the location where damage may exist. This method has a low requirement for signal quality. It only needs to compare the characteristic parameters of the Lamb wave signals before and after damage, and a set of damage indexes are obtained to evaluate the damage probability. Then, the damage can be quickly imaged according to the damage probability of each position [53-56]. Tanaka et al. used the windowed energy arrival method to improve the reliability of this method [57]. Giurgiutiu et al. studied that the relative temperature sensitivity of the antiresonance frequency is approximately $63.1 \times 10^{-6} /{ }^{\circ} \mathrm{C}$ and the relative temperature sensitivity of the antiresonance amplitude is approximately $3.31 \times 10^{-3} /{ }^{\circ} \mathrm{C}[58]$. Liu et al. synthesized time reversal imaging method and the probability-based diagnostic imaging method to detect the delamination in the composite plate, which can solve the problem of the uneven probability distribution and improve the accuracy of imaging without selecting a threshold to the delamination image [59]. The present studies showed that this method does not depend on the Lamb wave velocity in the structure. Therefore, the probability-based diagnostic imaging method is very suitable for anisotropic plates.

However, the dimensions of an aircraft pallet are large, 88 or $96 " \times 125$ " (width $\times$ length). Thus, the probability-based diagnostic imaging method needs many piezoelectric transducer sensors distributed on the aircraft pallet. The number of actuator-sensor paths increases dramatically with the number of sensors and is calculated as $\mathrm{C}(N, 2)$ (where $N$ is the number 


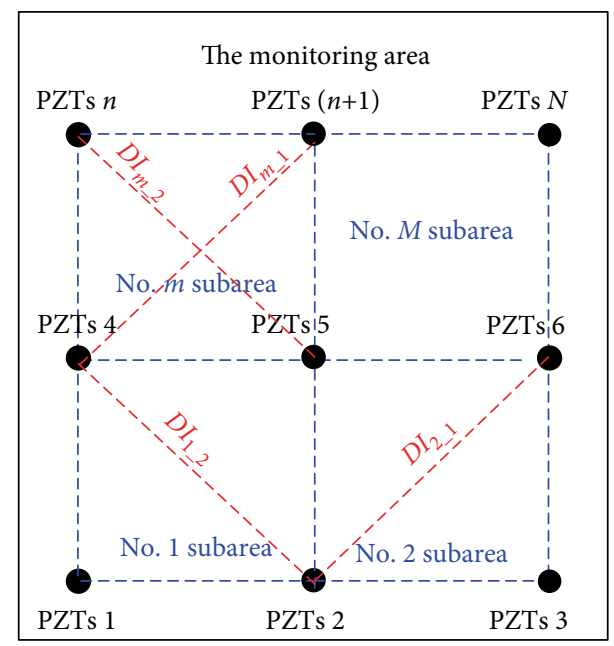

FIGURE 2: Diagram of damage region identification.

of piezoelectric transducer sensors). For example, the number of actuator-sensor paths is 105 with 15 piezoelectric transducer sensors, which will increase to 120 with 16 piezoelectric transducer sensors. The number of image pixels in structural images also increases for an aircraft pallet with large dimensions. The computational cost will rapidly increase with large numbers of actuator-sensor paths and pixels. Therefore, a new aircraft pallet damage monitoring method based on damage subarea identification and probability-based diagnostic imaging is proposed in this paper. First, the large monitoring area is divided into small subareas. Second, the subarea where the aircraft pallet is damaged is identified according to the diagonal damage index of the subarea. Then, the structural damage probability image of the damaged subarea is obtained using the probability-based diagnostic imaging method. Finally, the aircraft pallet damage is located according to the damage subarea position.

The rest of this paper is organized as follows. The principle of aircraft pallet damage monitoring is described in Section 2. In Section 3, the frequency selection and aircraft pallet damage simulation are studied. In Section 4, the proposed aircraft pallet damage monitoring method is validated on a specimen. Finally, conclusions are provided in Section 5.

\section{The Principle of Aircraft Pallet Damage Monitoring}

2.1. Damage Index Calculation. The structure transfer function of the aircraft pallet will change after damage, which affects the amplitude and phase of the sensor signal. Therefore, the damage index is calculated by Equation (1), which is based on the envelope of the damage scattering signal and the health reference signal, and is sensitive for detecting small variations in the time domain $[60,61]$. In Equation $(1),\left(f_{\mathrm{OM}}(t)-f_{\mathrm{HR}}(t)\right)$ is the damage scattering signal.

$$
D I=\frac{\int\left|f_{\mathrm{OM}}(t)-f_{\mathrm{HR}}(t)\right| \mathrm{d} t}{\int\left|f_{\mathrm{HR}}(t)\right| \mathrm{d} t},
$$

where $D I$ is the damage index of the actuator-sensor path. $f_{\mathrm{OM}}(t)$ and $f_{\mathrm{HR}}(t)$ are the online monitoring signal and

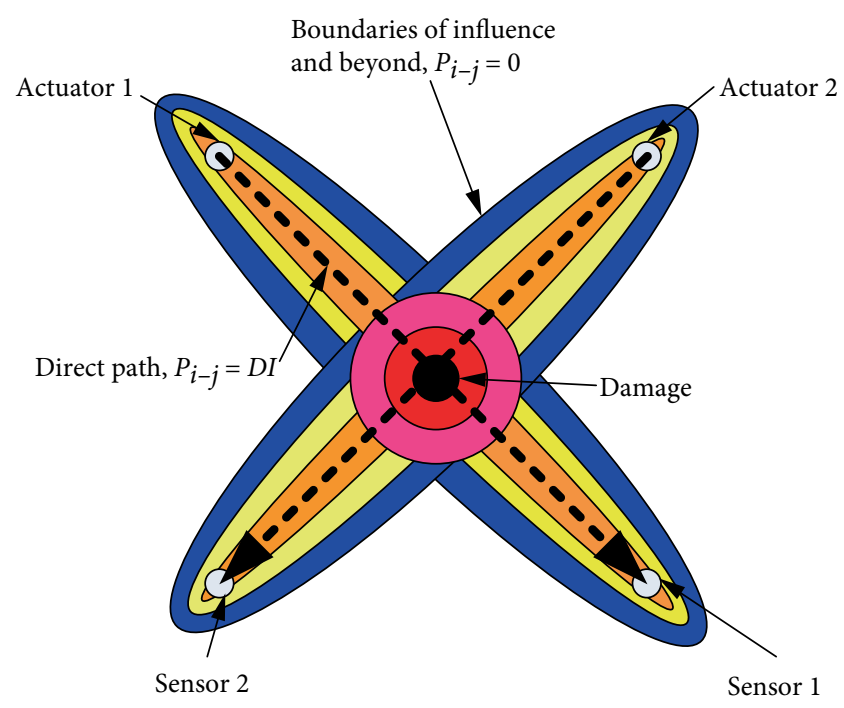

FIGURE 3: Diagram of probability-based diagnostic imaging.

health reference signal, respectively, and $t$ is the sampling time.

2.2. Damage Subarea Identification. According to the task requirements of SHM, the entire monitoring area is divided into $M$ rectangular subareas, which are numbered as the No. 1 subarea, No. 2 subarea, ......., No. $m$ subarea, ....... No. $M$ subarea. A piezoelectric transducer sensor is placed at each vertex of the rectangular subareas, and a total of $N$ piezoelectric transducer sensors are arranged over the entire monitoring area. The piezoelectric transducer sensors are numbered PZTs 1, PZTs $2, \ldots \ldots .$, PZTs $n, \ldots \ldots .$, PZTs $N$ in turn, as shown in Figure 2.

The damage index of one diagonal of each subarea is calculated by Equation (1); for example, the PZTs 2 actuator PZTs 6 sensor path is a diagonal of the No. 2 subarea in Figure 2. Then, the average value $D I_{a}$ of the diagonal damage indexes is calculated by Equation (2) and set to be the damage threshold.

$$
D I_{a}=\frac{1}{M} \sum_{m=1}^{M} D I_{m \_1},
$$

where $D I_{m_{-}}$is one diagonal damage index of the No. $m$ subarea, and $m$ is the number of the subarea.

The subareas whose diagonal damage index is greater than the damage threshold $D I_{a}$ are selected as the suspected damage subareas. A suspected damage subarea is identified as a damage subarea if there is only one suspected damage subarea. Otherwise, the damage index of the other diagonal of the suspected damage subareas is calculated, and the average value of the two diagonal damage indexes is obtained. Then, the suspected damage subarea with the largest average value of the two diagonal damage indexes is identified as the damage subarea.

2.3. Probability-Based Diagnostic Imaging. First, the damage indexes of the other actuator-sensor paths of the damage subarea are calculated. Second, the damage subarea is divided into pixels according to the task requirements of SHM. In addition, the damage probability of each pixel in the PZTs $i$ actuator-PZTs $j$ sensor path is calculated by Equation (3). 


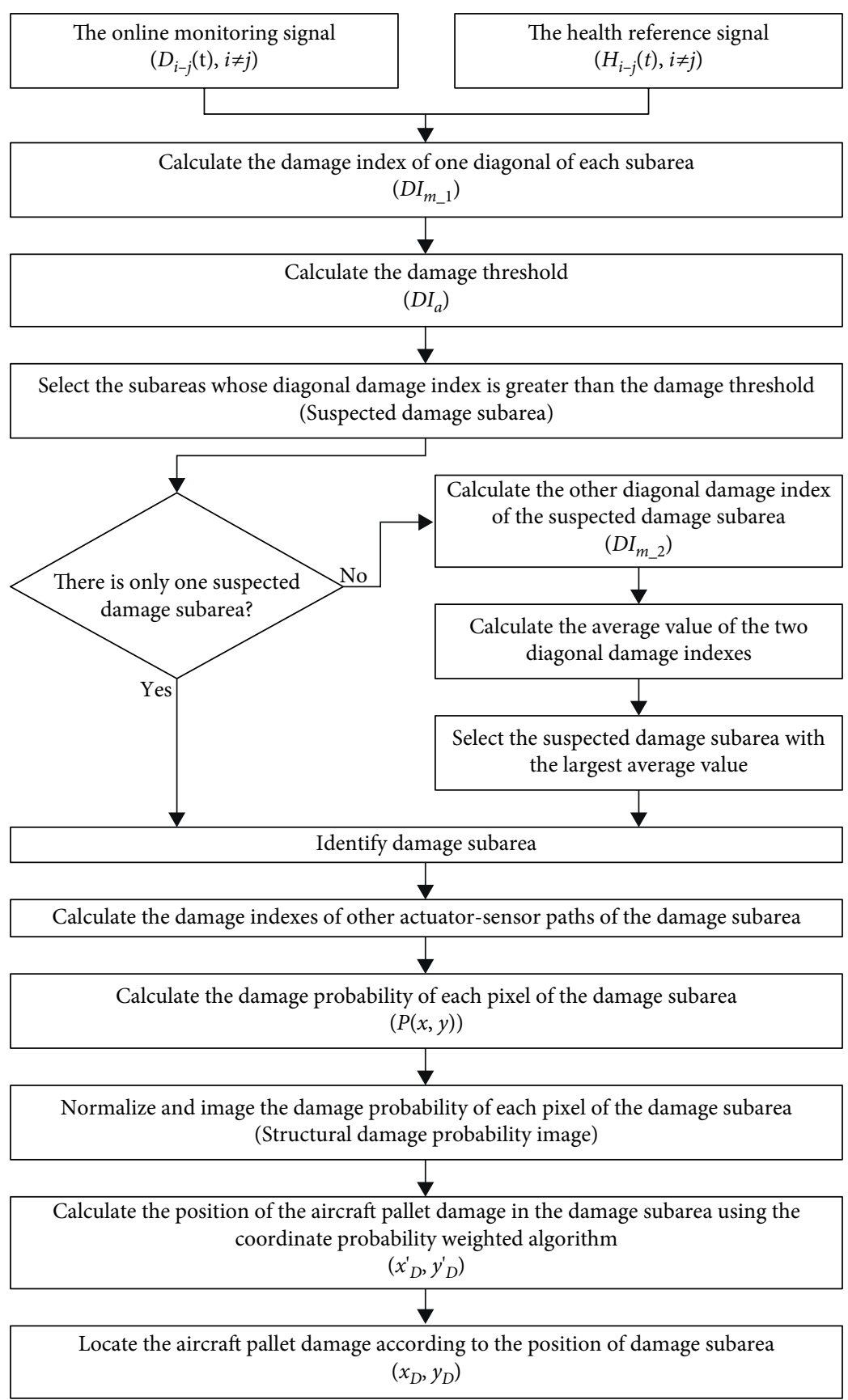

FIGURE 4: Diagram of the aircraft pallet damage monitoring method.

$$
P_{i-j}(x, y)=D I_{i-j}\left[\frac{B-R_{i-j}^{\prime}(x, y)}{B-1}\right],
$$

where $P_{i-j}(x, y)$ is the damage probability of pixel $(x, y)$ in the PZTs $i$ actuator-PZTs $j$ sensor path. $(x, y)$ is the coordinates of the pixel. $D I_{i-j}$ is the damage index of the PZTs $i$ actuator-PZTs $j$ sensor path. $B$ is a scaling parameter controlling the size of the effective distribution area. $R_{i-j}^{\prime}(x, y)$ is a weight to regulate the area of influence of the damage along a particular sensing path in the sensor network as detailed elsewhere, which is expressed as equations 4(a) and 4(b).

$$
R_{i-j}^{\prime}(x, y)=R_{i-j}(x, y), \text { if } R_{i-j}(x, y)<B,
$$

$$
R_{i-j}^{\prime}(x, y)=B, \text { if } R_{i-j}(x, y) \geq B
$$

where

$$
R_{i-j}(x, y)=\frac{\sqrt{\left(x-x_{i}\right)^{2}+\left(y-y_{i}\right)^{2}}+\sqrt{\left(x-x_{j}\right)^{2}+\left(y-y_{j}\right)^{2}}}{\sqrt{\left(x_{j}-x_{i}\right)^{2}+\left(y_{j}-y_{i}\right)^{2}}},
$$

$\left(x_{i}, y_{i}\right)$ is the coordinates of PZTs $i .\left(x_{j}, y_{j}\right)$ is the coordinates of PZTs $j$. 
The damage probability of the pixels in each actuator-sensor path of the damage subarea can be calculated by Equation (3). Then, the damage probability $P(x, y)$ of pixel $(x, y)$ can be obtained by summing all the probability values for each actuator-sensor path, which is represented as Equation (6).

$$
P(x, y)=\sum_{i} \sum_{j} P_{i-j}(x, y) \text {. }
$$

The damage probabilities of all pixels in the damage subarea are calculated and normalized. Then, the structural damage probability image of the damage subarea can be obtained by imaging the normalized damage probabilities, as shown in Figure 3. The aircraft pallet damage position in the damage subarea can be calculated using the coordinate probability weighted algorithm, which is expressed as Equation (7). Finally, the aircraft pallet damage can be localized based on the damage subarea position.

$$
\begin{aligned}
& x_{D}^{\prime}=\frac{\sum_{s} \sum_{k} x_{s} \cdot P\left(x_{s}, y_{k}\right)}{\sum_{s} \sum_{k} P\left(x_{s}, y_{k}\right)}, \\
& y_{D}^{\prime}=\frac{\sum_{s} \sum_{k} y_{k} \cdot P\left(x_{s}, y_{k}\right)}{\sum_{s} \sum_{k} P\left(x_{s}, y_{k}\right)},
\end{aligned}
$$

where $\left(x_{D}^{\prime}, y_{D}^{\prime}\right)$ is the coordinates of the aircraft pallet damage in the damage subarea. $P\left(x_{s}, y_{k}\right)$ is the damage probability at position $\left(x_{s}, y_{k}\right)$.

2.4. Aircraft Pallet Damage Monitoring Process. Based on the above detailed discussion of the aircraft pallet damage monitoring, the entire aircraft pallet damage monitoring process is shown in Figure 4. First, the entire monitoring area is divided into rectangular subareas. Then, the damage subarea is identified based on the diagonal damage index. The position of the aircraft pallet damage in the damage subarea is calculated using the probability-based diagnostic imaging method and the coordinate probability weighted algorithm. Finally, the aircraft pallet damage is localized according to the damage subarea position.

\section{Frequency Selection and Aircraft Pallet Damage Simulation}

To experimentally validate the proposed method, experimental studies of the frequency selection and aircraft pallet damage simulation are first carried out. According to the aircraft pallet production process, a small specimen of $500 \mathrm{~mm} \times 500 \mathrm{~mm}$ (length $\times$ width) is made. The upper layer of the specimen is a 7075 aluminum alloy plate of $500 \mathrm{~mm} \times 500 \mathrm{~mm} \times 2 \mathrm{~mm}$ (length $\times$ width $\times$ thickness), and the lower layer is 5 balsa wood plates of $500 \mathrm{~mm} \times 100 \mathrm{~mm} \times 10 \mathrm{~mm}$ (length $\times$ width $\times$ thickness). The upper and lower layers are bonded together by epoxy resin adhesive. The type, diameter and thickness of the piezoelectric transducer sensor are PZT-5A, $8 \mathrm{~mm}$, and $0.48 \mathrm{~mm}$, respectively. As shown in Figure 5, the experimental system for the frequency selection and aircraft pallet damage simulation consists of an aircraft pallet specimen, an integrated SHM system and two piezoelectric transducer sensors. The integrated SHM system is adopted to excite and acquire Lamb wave signals.

Two piezoelectric transducer sensors are placed on the middle of the test specimen as actuator and sensor elements, as shown in Figure 5(c), and the distance between the centers of the two piezoelectric transducer sensors is $150 \mathrm{~mm}$. The distances between the actuator element and the specimen boundaries are $200 \mathrm{~mm}$ and $250 \mathrm{~mm}$, and the distances between the sensor element and the specimen boundaries are $150 \mathrm{~mm}$ and $250 \mathrm{~mm}$. The vertical distances from the damage location to the two piezoelectric transducer sensors and the direct paths of the two piezoelectric transducer sensors are both $75 \mathrm{~mm}$.

The excitation signal is a five-cycle sine burst modulated by a Hanning window. The center frequency of the excitation signal ranges from $40 \mathrm{kHz}$ to $450 \mathrm{kHz}$ with an interval of $5 \mathrm{kHz}$, and the amplitude of the excitation signal is \pm 70 volts. The sampling rate is $10 \mathrm{MS} / \mathrm{s}$, and the sampling length is 10000 samples, including 1000 presamples.

The experimental process is described as follows.

(1) For the test specimen in the healthy state, Lamb wave signals of the piezoelectric transducer sensor are acquired as the health reference signals, $f_{\mathrm{HR}}$.

(2) A $1 \mathrm{~kg}$ steel ball is pasted at the damage location to change the local structural stiffness, which causes scattering of the Lamb wave [62]. The corresponding Lamb wave signals of the piezoelectric transducer sensor are acquired as the steel ball damage monitoring signals, $f_{\mathrm{SB}}$.

(3) After remaining in the healthy state for one month, the Lamb wave signals of the piezoelectric transducer sensor are acquired as the state microvariation monitoring signals, $f_{\mathrm{SM}}$.

(4) Taking the damage position as the center point, balsa wood squares with side lengths of $10 \mathrm{~mm}, 20 \mathrm{~mm}$, $30 \mathrm{~mm}, 40 \mathrm{~mm}$, and $50 \mathrm{~mm}$ are removed in turn. The corresponding Lamb wave signals of the piezoelectric transducer sensor are acquired as the real damage online monitoring signals, $f_{\mathrm{RD}}$.

Figure 6 shows the health reference signal, and the damage scattering signal of the steel ball when the actuating central frequency is $100 \mathrm{kHz}$. The damage index $0.1411 \mathrm{can}$ be calculated by Equation (1).

The damage indexes of the steel ball damage, state microvariation and real damage at different frequencies are calculated by Equation (1), as shown in Figure 7.

Figure 7 shows that the Lamb wave is sensitive to aircraft pallet damage at frequencies from $50 \mathrm{kHz}$ to $150 \mathrm{kHz}$. The damage indexes of the state microvariation are less than 0.1 at all frequencies and are less than those for the steel ball and real damage. The damage indexes of the steel ball are less than those for all real damages in the frequency range from $95 \mathrm{kHz}$ to $125 \mathrm{kHz}$. Therefore, the aircraft pallet damage can be simulated by sticking a steel ball on the pallet, and the center frequency of the excitation signal of the Lamb wave should be selected from $95 \mathrm{kHz}$ to $125 \mathrm{kHz}$.

\section{Experimental Validation}

4.1. Experimental Setup. The experimental system for validation shown in Figure 8 consists of an aircraft pallet specimen, piezoelectric transducer sensors and an 


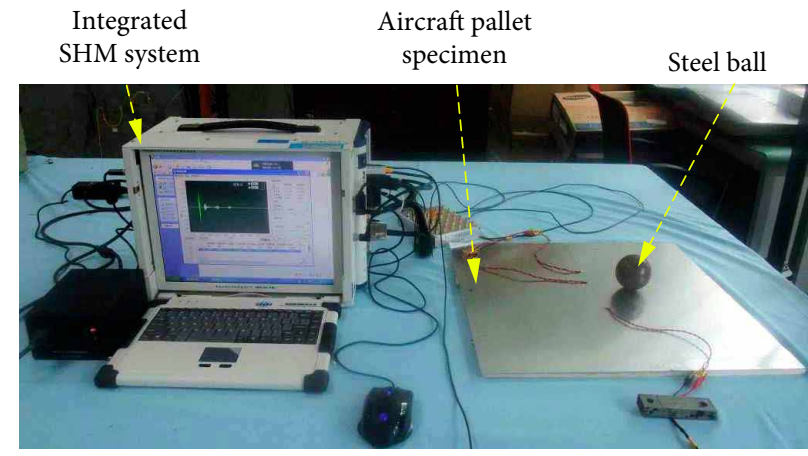

(a)

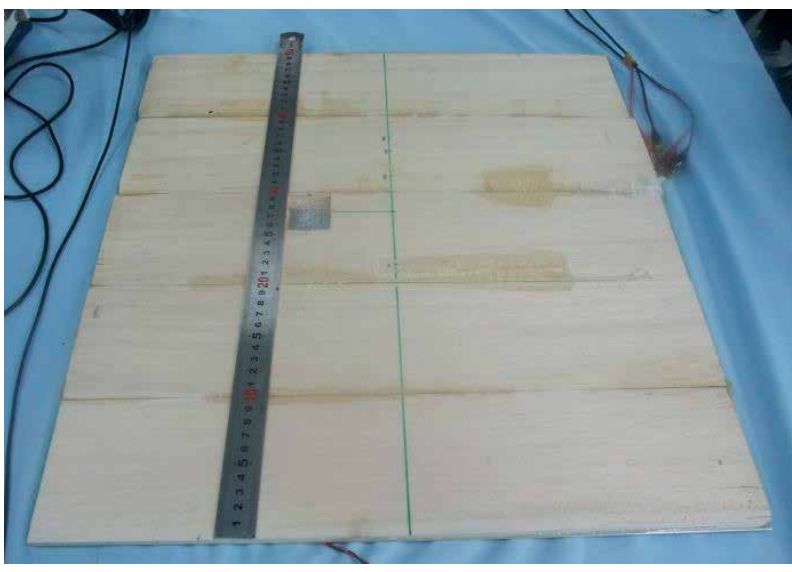

(b)

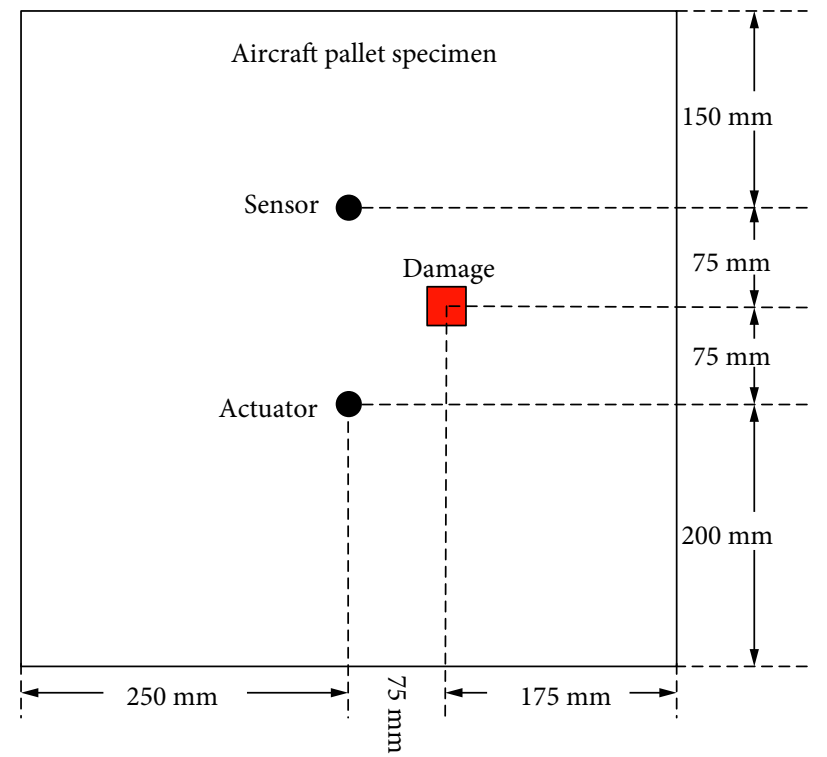

(c)

Figure 5: Illustration of the experimental system for frequency selection and aircraft pallet damage simulation. (a) Experimental setup; (b) real damage; (c) positions of piezoelectric transducer sensors and damage.

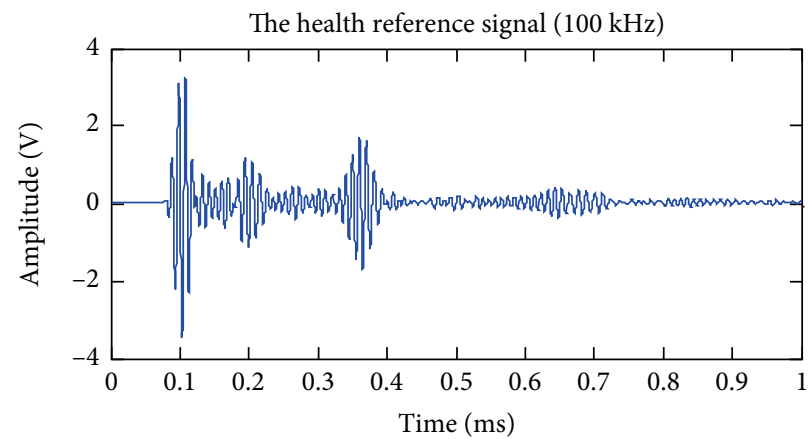

(a)

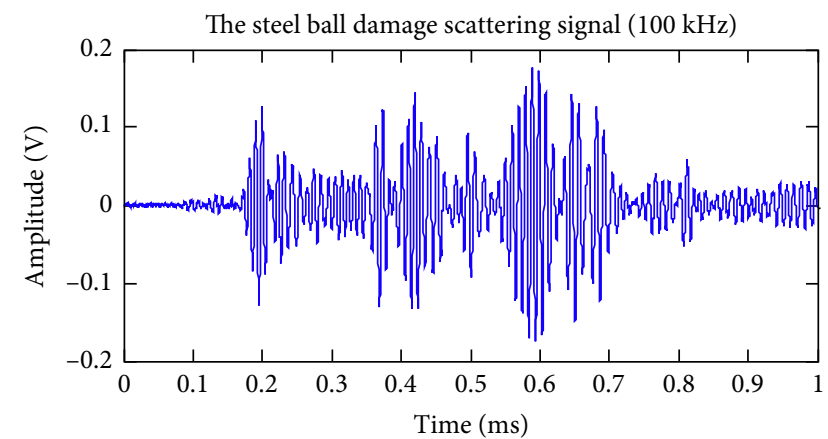

(b)

FIGURE 6: The monitoring signals with a central frequency of $100 \mathrm{kHz}$ in different condition. (a) The health reference signal; (b) the steel ball damage scattering signal.

integrated SHM system. The specimen is made according to the aircraft pallet production process. The dimensions of the specimen are $1000 \mathrm{~mm} \times 1000 \mathrm{~mm}$ (length $\times$ width). The upper layer of the specimen is a 7075 aluminum alloy plate of $1000 \mathrm{~mm} \times 1000 \mathrm{~mm} \times 2 \mathrm{~mm}$ (length $\times$ width $\times$ thickness), and the lower layer is 10 balsa wood plates of $1000 \mathrm{~mm} \times 100 \mathrm{~mm} \times 10 \mathrm{~mm} \quad$ (length $\times$ width $\times$ thickness). The two layers are bonded together by epoxy resin adhesive. 


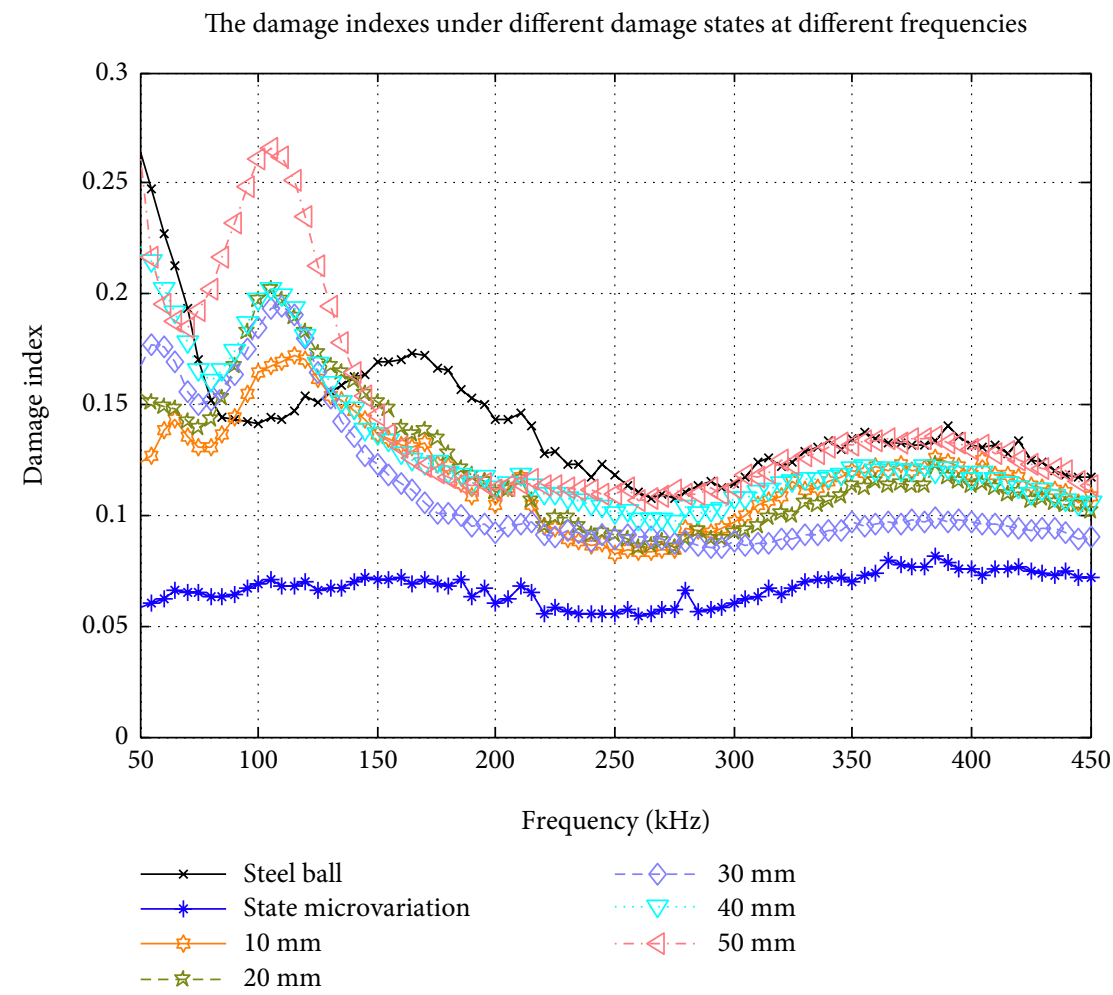

FIGURE 7: The damage indexes of the steel ball, state microvariation and real damage at different frequencies.

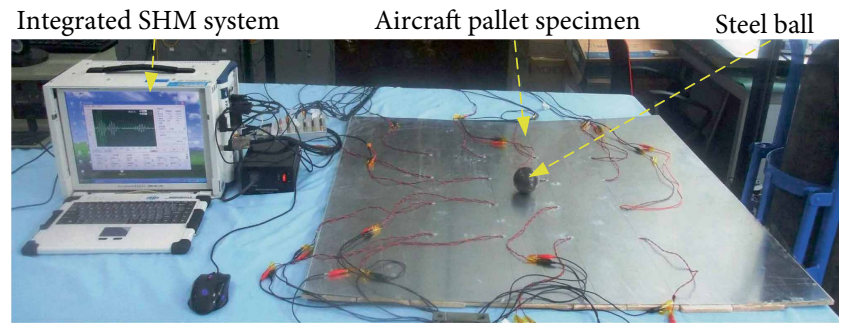

(a)

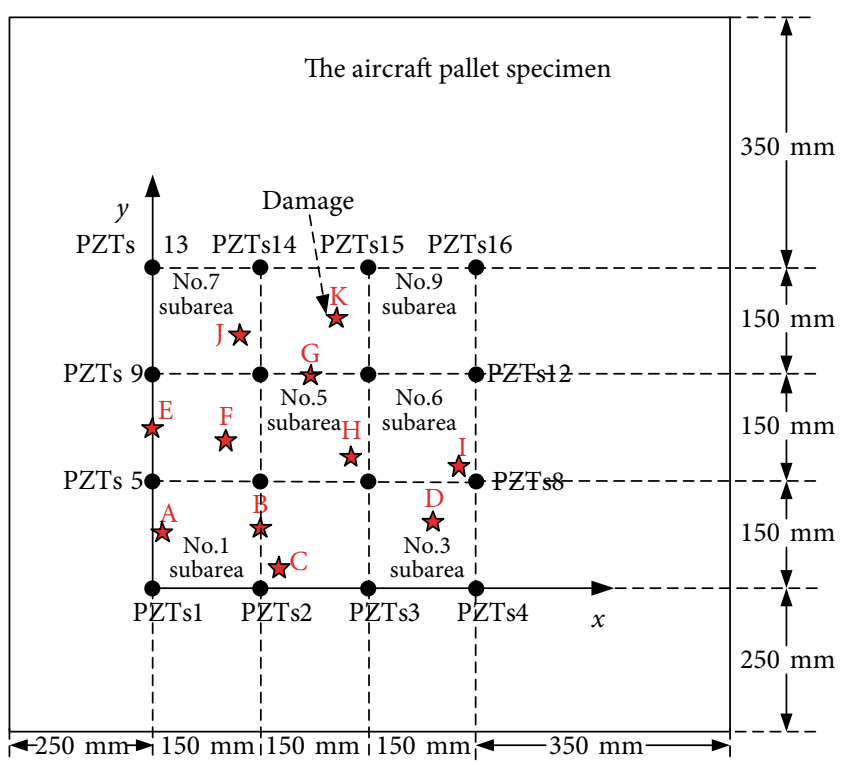

(b)

FIGURE 8: The experimental system for validation of the aircraft pallet damage monitoring method. (a) Experimental system; (b) piezoelectric transducer sensor placement and damage positions.
TABLE 1: Positions of the simulated damages.

\begin{tabular}{lc}
\hline Damage & Cartesian co-ordinates $(\mathrm{mm}, \mathrm{mm})$ \\
\hline A & $(10,75)$ \\
B & $(150,75)$ \\
C & $(180,50)$ \\
D & $(375,75)$ \\
E & $(0,225)$ \\
F & $(100,200)$ \\
G & $(225,300)$ \\
H & $(280,170)$ \\
I & $(420,190)$ \\
J & $(120,350)$ \\
K & $(270,340)$ \\
\hline
\end{tabular}

The entire monitoring structure is divided into 9 subareas, which are numbered as the No. 1 subarea, No. 2 subarea, ......, and No. 9 subarea from left to right and bottom to top, as shown in Figure 8. A piezoelectric transducer sensor is arranged at each of the four vertices of each subarea, and a total of 16 piezoelectric transducer sensors are arranged in the entire monitoring area. The piezoelectric transducer sensors are labeled PZTs 1, PZTs 2, ......, PZTs 16 from left to right and bottom to top. The distance between the centers of two adjacent piezoelectric transducer sensors is $\Delta x=150 \mathrm{~mm}$, and the centers of the outermost piezoelectric transducer sensor are $200 \mathrm{~mm}$ and $350 \mathrm{~mm}$ from the boundaries of the specimen. Building a two-dimensional Cartesian coordinate system in the specimen, PZTs 1 is taken as the origin, the horizontal direction from PZTs 1 to PZTs 4 is taken as the 


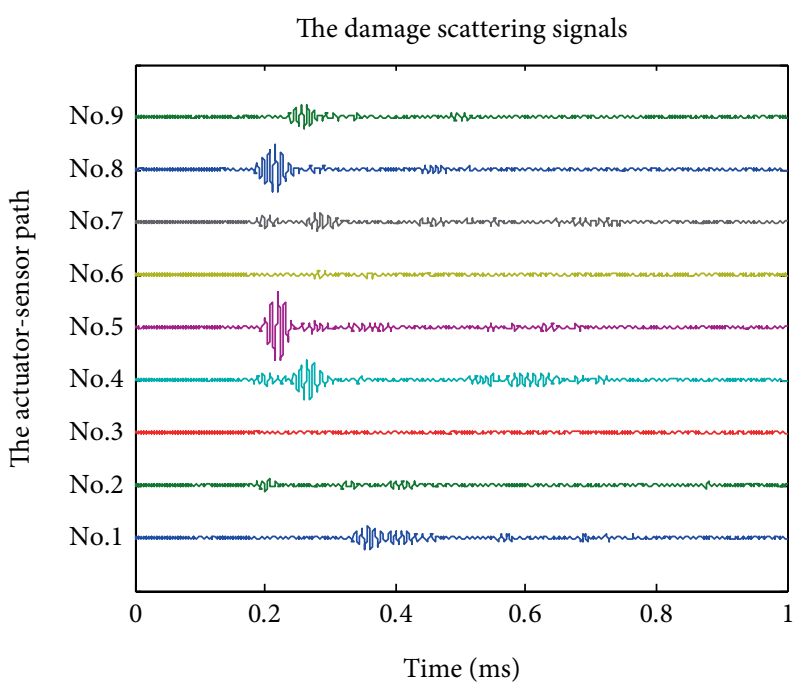

(a)

The health reference signals

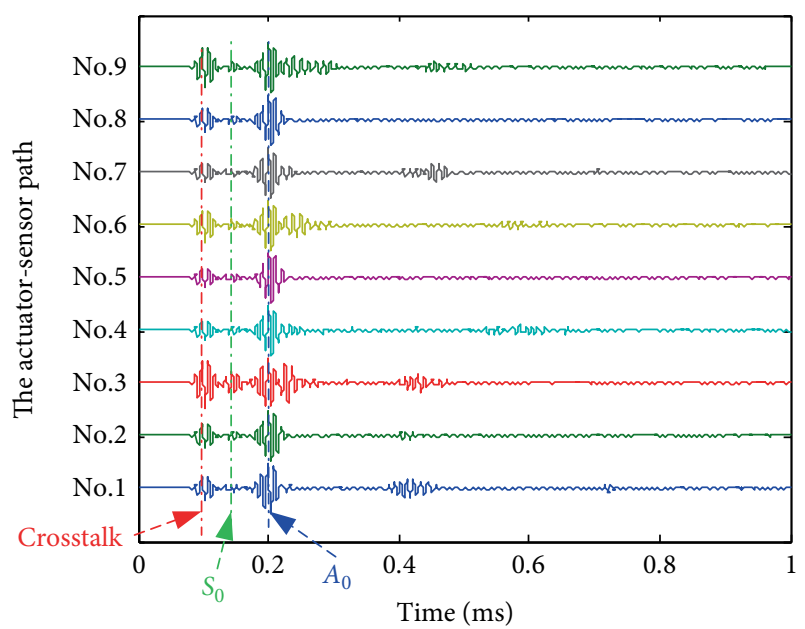

(b)

FIGURE 9: The damage scattering and health reference signals of a diagonal in each subarea. (a) The damage scattering signals; (b) the health reference signals.

$x$ axis, and the vertical direction from PZTs 1 to PZTs 13 is taken as the $y$ axis. As shown in Figure 8, the damages labeled $\mathrm{A}$ to $\mathrm{K}$ are applied to the structure by sticking a steel ball on the pallet. The positions of these damages are shown in Table 1.

In this experiment, the excitation signal is a five-cycle sine burst modulated by a Hanning window. The center frequency of the excitation signal is $100 \mathrm{kHz}$, and the amplitude is \pm 70 volts. The sampling rate is $10 \mathrm{MS} / \mathrm{s}$, and the sampling length is 10000 samples, including 1000 presamples. The trigger voltage is 6 volts.

4.2. Location Analysis of Typical Damage Signals. The aircraft pallet damage monitoring of position $\mathrm{G}$ is chosen as an example to show the localization process of the proposed method. The Lamb wave signals of each actuator-sensor path have been acquired as the health reference signals $f_{\mathrm{HR}}$ when the structure is in the healthy state. Damage is applied at position $\mathrm{G}$, and the corresponding Lamb wave signals of one diagonal of each

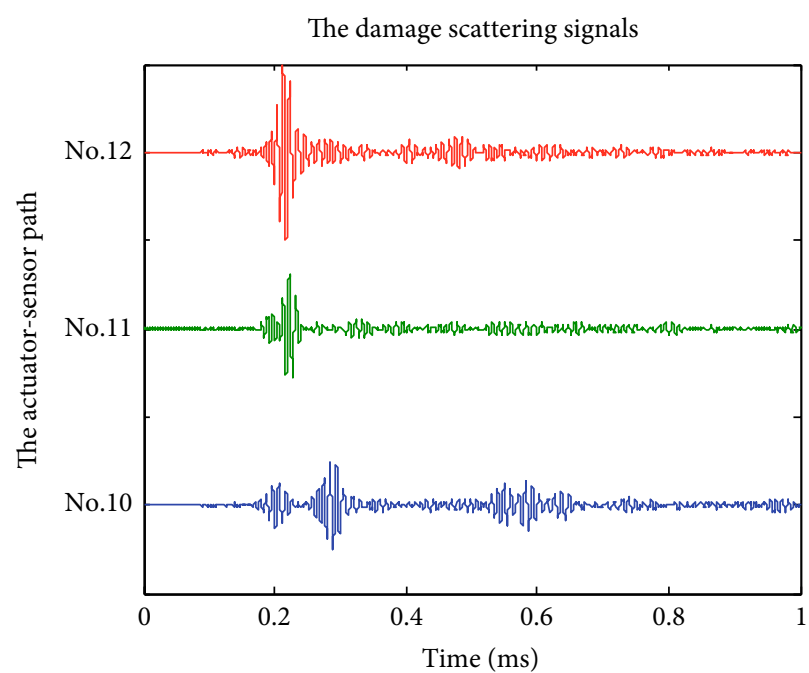

(a)

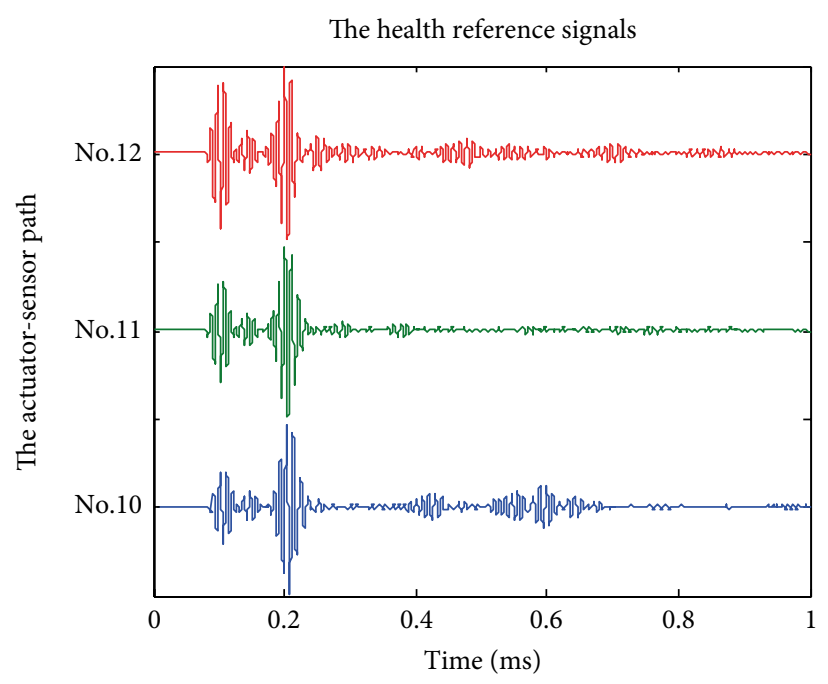

(b)

FIGURE 10: The damage scattering and health reference signals of the other diagonal in the suspected damage subareas. (a) The damage scattering signals; (b) the health reference signals.

TABLE 2: The damage indexes of the diagonal actuator-sensor path of each subarea.

\begin{tabular}{lcccc}
\hline $\begin{array}{l}\text { Subarea } \\
\text { number }\end{array}$ & $\begin{array}{c}\text { Actuator-sensor } \\
\text { path number }\end{array}$ & Actuator & Sensor & $\begin{array}{c}\text { Damage } \\
\text { index }\end{array}$ \\
\hline No. 1 & No. 1 & PZTs 1 & PZTs 6 & 0.0936 \\
No. 2 & No. 2 & PZTs 2 & PZTs 7 & 0.0919 \\
No. 3 & No. 3 & PZTs 3 & PZTs 8 & 0.0488 \\
No. 4 & No. 4 & PZTs 5 & PZTs 10 & 0.1459 \\
No. 5 & No. 5 & PZTs 6 & PZTs 11 & 0.1999 \\
No. 6 & No. 6 & PZTs 7 & PZTs 12 & 0.0613 \\
No. 7 & No. 7 & PZTs 9 & PZTs 14 & 0.1013 \\
No. 8 & No. 8 & PZTs 10 & PZTs 15 & 0.1704 \\
No. 9 & No. 9 & PZTs 11 & PZTs 16 & 0.1137 \\
\hline
\end{tabular}

subarea are acquired as the online monitoring signals $f_{\mathrm{OM}}$. The damage scattering signals $\left(f_{\mathrm{OM}}-f_{\mathrm{HR}}\right)$ are shown in Figure $9(\mathrm{a})$ and the corresponding health reference signals $f_{\mathrm{HR}}$ are shown in Figure 9(b). The diagonal actuator-sensor path network of 
TABLE 3: The damage indexes of the other diagonal actuator-sensor path of the 3 suspected damage subareas.

\begin{tabular}{lcccc}
\hline $\begin{array}{l}\text { Subarea } \\
\text { number }\end{array}$ & $\begin{array}{c}\text { Actuator-sensor } \\
\text { path number }\end{array}$ & Actuator & Sensor & $\begin{array}{c}\text { Damage } \\
\text { index }\end{array}$ \\
\hline No. 4 & No. 10 & PZTs 6 & PZTs 9 & 0.1151 \\
No. 5 & No. 11 & PZTs 7 & PZTs 10 & 0.1257 \\
No. 8 & No. 12 & PZTs 11 & PZTs 14 & 0.2038 \\
\hline
\end{tabular}

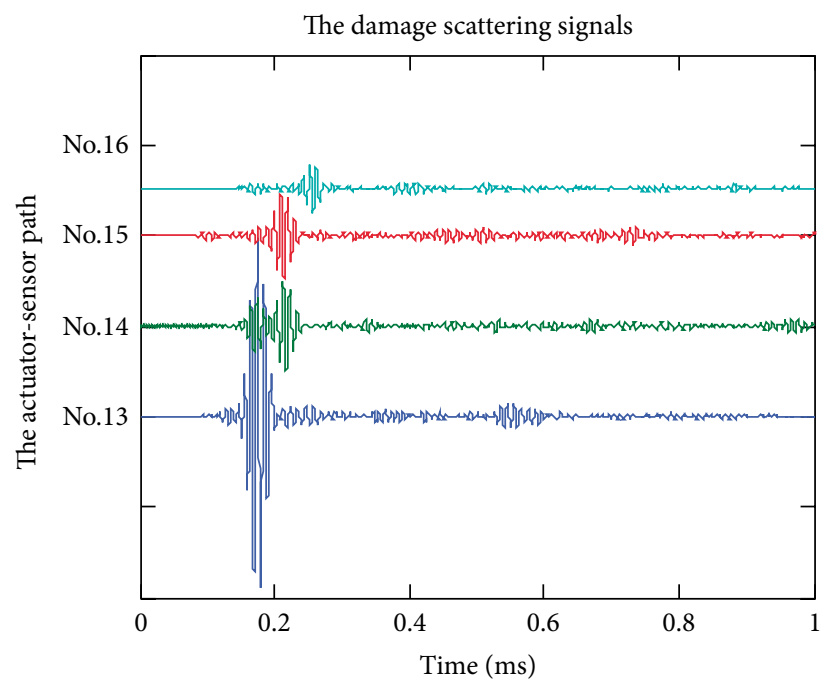

(a)

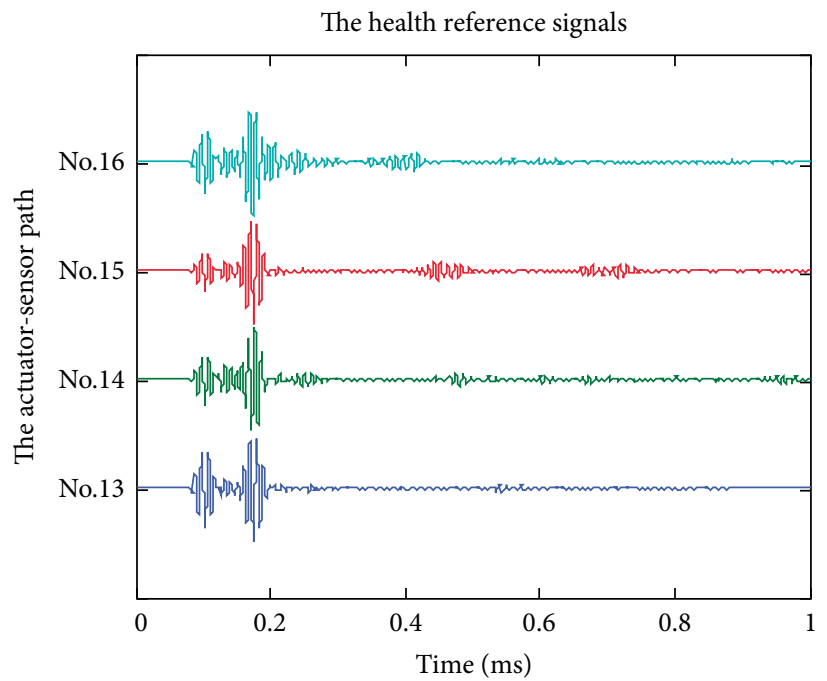

(b)

FIGURE 11: The damage scattering and health reference signals of the remaining actuator-sensor paths of the damage subarea. (a) The damage scattering signals; (b) The health reference signals.

each subarea is shown in Table 2. According to Figure 9, the amplitude of the Lamb wave $A_{0}$ mode is dominant at $100 \mathrm{kHz}$ in this experiment.

Based on Equation (1), the damage indexes of the diagonal actuator-sensor path of each subarea can be obtained, as shown in Table 2 . Then, the average value $D I_{a}=0.1141$ of the diagonal damage indexes can be calculated by Equation (2) and set to be the damage threshold. According to Table 2, the No. 4, No. 5 and No. 8 subareas are selected as the suspected
TABLE 4: The damage indexes of all the actuator-sensor paths of the damage subarea.

\begin{tabular}{lccc}
\hline $\begin{array}{l}\text { Actuator-sensor path } \\
\text { number }\end{array}$ & Actuator & Sensor & Damage index \\
\hline No. 8 & PZTs 10 & PZTs 15 & 0.1704 \\
No. 12 & PZTs 11 & PZTs 14 & 0.2038 \\
No. 13 & PZTs 10 & PZTs 11 & 0.3273 \\
No. 14 & PZTs 10 & PZTs 14 & 0.1890 \\
No. 15 & PZTs 11 & PZTs 15 & 0.1281 \\
No. 16 & PZTs 14 & PZTs 15 & 0.1107 \\
\hline
\end{tabular}

Structural damage probability image of the damage subarea

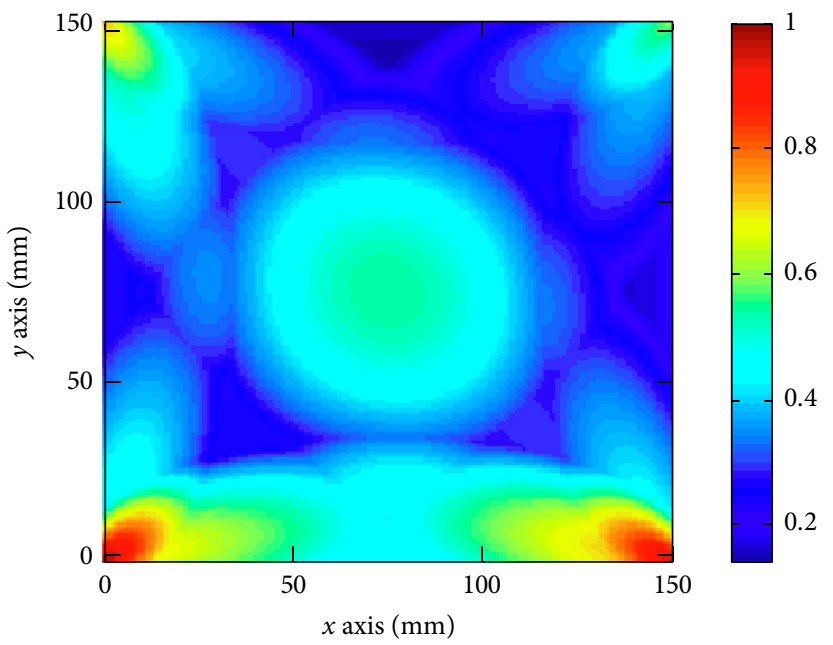

FIgURE 12: The structural damage probability image of the damage subarea.

TABLE 5: Damage localization results for all damages.

\begin{tabular}{lccc}
\hline Damage & $\begin{array}{c}\text { Actual coordinates } \\
(\mathrm{mm}, \mathrm{mm})\end{array}$ & $\begin{array}{c}\text { Localization } \\
\text { result }(\mathrm{mm}, \mathrm{mm})\end{array}$ & $\begin{array}{c}\text { Distance } \\
\text { error }(\mathrm{mm})\end{array}$ \\
\hline A & $(10,75)$ & $(13.48,88.15)$ & 13.6 \\
$\mathrm{~B}$ & $(150,75)$ & $(144.62,72.07)$ & 6.1 \\
$\mathrm{C}$ & $(180,50)$ & $(191.80,51.02)$ & 11.8 \\
$\mathrm{D}$ & $(375,75)$ & $(375.81,75.02)$ & 0.8 \\
$\mathrm{E}$ & $(0,225)$ & $(9.42,237.32)$ & 15.5 \\
$\mathrm{~F}$ & $(100,200)$ & $(100.69,218.82)$ & 18.8 \\
$\mathrm{G}$ & $(225,300)$ & $(225.97,308.36)$ & 8.4 \\
$\mathrm{H}$ & $(280,170)$ & $(267.10,182.22)$ & 17.8 \\
$\mathrm{I}$ & $(420,190)$ & $(421.90,201.48)$ & 11.6 \\
$\mathrm{~J}$ & $(120,350)$ & $(118.79,369.38)$ & 19.4 \\
$\mathrm{~K}$ & $(270,340)$ & $(259.33,348.25)$ & 13.5 \\
\hline
\end{tabular}

damage subareas because their diagonal damage indexes are greater than the average value (damage threshold).

Because there are 3 suspected damage subareas, the online monitoring signals of the other diagonal of the No. 4, No. 5 and No. 8 subareas are acquired with the parameter settings of the experimental equipment unchanged. The damage scattering signals are shown in Figure 10(a), and the corresponding health reference signals $f_{\mathrm{HR}}$ are shown in Figure 10(b). The other diagonal actuator-sensor path networks of the 3 suspected damage 
subareas are shown in Table 3. The damage indexes of the other diagonal actuator-sensor paths of the 3 suspected damage subareas can be calculated by Equation (1), as shown in Table 3. Then, the average value of the two diagonal damage indexes of the 3 suspected damage subareas can be obtained. Therefore, the No. 8 subarea can be identified as the damage subarea because its average value of the two diagonal damage indexes is the largest among the 3 suspected damage subareas.

The online monitoring signals of the remaining actuator-sensor paths of the damage subarea (No. 8 subarea) are acquired with the parameter settings of the experimental equipment unchanged. The damage scattering signals are shown in Figure 11(a), and the corresponding health reference signals $f_{\mathrm{HR}}$ are shown in Figure 11(b). Then, the damage indexes of all the actuator-sensor paths of the damage subarea can be obtained, as shown in Table 4 .

A new Cartesian coordinate system is built for the damage subarea (No. 8 subarea), which has PZTs 10 as the origin, the horizontal direction from PZTs 10 to PZTs 11 as the $x$ axis, and the vertical direction from PZTs 10 to PZTs 14 as the $y$ axis. The coordinate resolution and the scaling parameter are set to $1 \mathrm{~mm}$ and 1.1 , respectively. Then, the damage probability of each pixel in the damage subarea (No. 8 subarea) is calculated by Equation (3), as shown in Figure 12. The aircraft pallet damage position of $(75.97,8.36) \mathrm{mm}$ in the damage subarea can be calculated using the coordinate probability weighted algorithm. Finally, according to the position of $(150,300) \mathrm{mm}$ of PZTs 10, the aircraft pallet damage position of (225.97, $308.36) \mathrm{mm}$ in the entire specimen can be localized, and the damage localization error is $8.4 \mathrm{~mm}$.

It can be seen from the entire aircraft pallet damage monitoring process that, the number of actuator-sensor paths is 16 , and the number of image pixels is $151 \times 151=22801$. However, for the traditional probability-based diagnostic imaging method, the number of actuator-sensor paths is $C(16,2)=120$, and the number of image pixels is $451 \times 451=203401$. Therefore, the proposed method is very suitable for the large aircraft pallets.

4.3. Verification Result. According to the aircraft pallet damage imaging and localization process for position $\mathrm{G}$ discussed above, the aircraft pallet damage localization results and the localization errors of the 11 damages are listed in Table 5. It is indicate that the aircraft pallet damage localization results are in good agreement with the actual damage positions, and the maximum aircraft pallet damage localization error is less than $20 \mathrm{~mm}$.

\section{Conclusions}

This paper proposes an aircraft pallet damage monitoring method based on damage subarea identification and probability-based diagnostic imaging. The large aircraft pallet monitoring area is first divided into small subareas. Then, the damage indexes of only a diagonal of the subarea are calculated, which can reduce the computational cost of the actuator-sensor paths. After the damage subarea is identified based on the diagonal damage indexes, aircraft pallet damage imaging and localization are performed only in the small damage subarea, which can reduce the computational cost of the image pixels. Thus, the proposed method is suitable for large aircraft pallets. The feasibility of the method is validated on an aircraft pallet specimen. The validation results show that the aircraft pallet damage localization errors are less than $2 \mathrm{~cm}$. However, detailed research needs to be performed on real full-scale aircraft pallets and damage scenarios in the future. In addition, the grid shape and size of the subarea, and the temperature effect of this method also need to be specially studied.

\section{Data Availability}

The data used to support the findings of this study are available from the corresponding author upon request.

\section{Conflicts of Interest}

The authors declare that they have no conflicts of interest.

\section{Funding}

This research was supported by the National Natural Science Foundation of China (No. 51705530), the Xuzhou Science and Technology Plan Project (No. KH17010), the Air Force Service Academy Youth Research Fund Project (No. KY2018D002A) and the 111 Project (No. D18003).

\section{Acknowledgments}

The work also benefited from the assistance of Professor Shenfang Yuan and Lei Qiu. The authors thank American Journal Experts (AJE) for the English language editing.

\section{References}

[1] F. T. S. Chan, R. Bhagwat, N. Kumar, M. K. Tiwari, and P. Lam, "Development of a decision support system for air-cargo pallets loading problem: a case study," Expert Systems with Applications, vol. 31, no. 3, pp. 472-485, 2006.

[2] "Uni-top airlines opens wuhan-luxembourg cargo service," 2018, http://www.sasac.gov.cn/n2588025/n2588129/c8539552/ content.html.

[3] T. R. Hay, R. L. Royer, H. Gao, X. Zhao, and J. L. Rose, "A comparison of embedded sensor lamb wave ultrasonic tomography approaches for material loss detection," Smart Materials and Structures, vol. 15, no. 4, pp. 946-951, 2006.

[4] J. Zhang, G. Y. Tian, and A. B. Zhao, "Passive RFID sensor systems for crack detection \& characterization," NDT \& $E$ International, vol. 86, pp. 89-99, 2016.

[5] M. Mitra and S. Gopalakrishnan, "Guided wave based structural health monitoring: a review," Smart Materials and Structures, vol. 25, no. 5, p. 053001, 2016.

[6] J. Jiao, X. Meng, C. He, and B. Wu, "Nonlinear Lamb wavemixing technique for micro-crack detection in plates," NDT \& E International, vol. 85, pp. 63-71, 2017.

[7] K. Lonkar and F. K. Chang, "Modeling of piezo-induced ultrasonic wave propagation in composite structures using 
layered solid spectral element," Structural Health Monitoring: An International Journal, vol. 13, no. 1, pp. 50-67, 2014.

[8] T. Stepinski, M. Michał, and A. Martowicz, "Interdigital lamb wave transducers for applications in structural health monitoring," NDT \& E International, vol. 86, pp. 199-210, 2017.

[9] K. S. Ramadan, D. Sameoto, and S. Evoy, "A review of piezoelectric polymers as functional materials for electromechanical transducers," Smart Materials and Structures, vol. 23, no. 3, pp. 33001-33026, 2014.

[10] W. Li, Q. Kong, S. C. M. Ho, Y. L. Mo, and G. Song, "Feasibility study of using smart aggregates as embedded acoustic emission sensors for health monitoring of concrete structures," Smart Materials and Structures, vol. 25, no. 11, Article ID 115031, 2016.

[11] J. Zhu, S. C. M. Ho, D. Patil, N. Wang, R. Hirsch, and G. Song, "Underwater pipeline impact localization using piezoceramic transducers," Smart Materials and Structures, vol. 26, p. 107002, 2017.

[12] F. Baptista, D. Budoya, V. Almeida, and J. Ulson, "An experimental study on the effect of temperature on piezoelectric sensors for impedance-based structural health monitoring," Sensors, vol. 14, pp. 1208-1227, 2014.

[13] T. Wandowski, P. H. Malinowski, and W. M. Ostachowicz, "Circular sensing networks for guided waves based structural health monitoring," Mechanical Systems and Signal Processing, vol. 66-67, pp. 248-267, 2015.

[14] Q. Huan, H. Miao, and F. Li, "A variable-frequency structural health monitoring system based on omnidirectional shear horizontal wave piezoelectric transducers," Smart Materials and Structures, vol. 27, p. 025008, 2018.

[15] X. Qing, W. Li, Y. Wang, and H. Sun, "Piezoelectric TransducerBased Structural Health Monitoring for Aircraft Applications," Sensors, vol. 19, p. 545, 2019.

[16] Y. Liang, D. Li, Q. Kong, and G. Song, "Load monitoring of the pin-connected structure using time reversal technique and piezoceramic transducers-a feasibility study," IEEE Sensors Journal, vol. 16, pp. 7958-7966, 2016.

[17] T. Jiang, Q. Kong, W. Wang, L. Huo, and G. Song, "Monitoring of grouting compactness in a post-tensioning tendon duct using piezoceramic transducers," Sensors, vol. 16, p. 1343, 2016.

[18] T. Jiang, Q. Kong, D. Patil, Z. Luo, L. Huo, and G. Song, "Detection of debonding between fiber reinforced polymer bar and concrete structure using piezoceramic transducers and wavelet packet analysis," IEEE Sensors Journal, vol. 17, pp. 1992-1998, 2017.

[19] Q. Kong, H. Chen, Y. Mo, and G. Song, "Real-time monitoring of water content in sandy soil using shear mode piezoceramic transducers and active sensing-a feasibility study," Sensors, vol. 17, p. 2395, 2017.

[20] L. Huo, X. Li, H. Li, Z. Wang, and G. Song, "Dynamic modelling of embeddable piezoceramic transducers," Sensors, vol. 17, p. 2801, 2017.

[21] T. Jiang, Q. Kong, Z. Peng et al., "Monitoring of corrosioninduced degradation in prestressed concrete structure using embedded piezoceramic-based transducers," IEEE Sensors Journal, vol. 17, pp. 5823-5830, 2017.

[22] K. Xu, Q. Deng, L. Cai, S. Ho, and G. Song, "Damage detection of a concrete column subject to blast loads using embedded piezoceramic transducers," Sensors, vol. 18, p. $1377,2018$.
[23] S. Roy, P. Ladpli, and F. K. Chang, "Load monitoring and compensation strategies for guided-waves based structural health monitoring using piezoelectric transducers," Journal of Sound and Vibration, vol. 351, pp. 206-220, 2015.

[24] P. Kudela, M. Radzienski, W. Ostachowicz, and Z. Yang, "Structural health monitoring system based on a concept of lamb wave focusing by the piezoelectric array," Mechanicsl Systems and Signal Processing, vol. 108, pp. 21-32, 2018.

[25] A. Migot, Y. Bhuiyan, and V. Giurgiutiu, "Numerical and experimental investigation of damage severity estimation using Lamb wave-based imaging methods," Journal of Intelligent Material Systems and Structures, vol. 30, no. 4, pp. 618-635, 2019.

[26] C. H. Wang, J. T. Rose, and F. K. Chang, "A synthetic time reversal imaging method for structural health monitoring," Smart Materials and Structures, vol. 13, no. 2, pp. 415-423, 2004.

[27] L. Qiu, M. Liu, X. Qing, and S. Yuan, "A quantitative multidamage monitoring method for large-scale complex composite," Structural Health Monitoring: An International Journal, vol. 12, no. 3, pp. 183-196, 2013.

[28] S. Fu, L. Shi, Y. Zhou, and Z. Fu, "Enhancement of Lamb wave imaging resolution by step pulse excitation and prewarping," Shock and Vibration, vol. 2015, pp. 1-8, 2015.

[29] G. Lu, Y. Li, T. Wang, H. Xiao, L. Huo, and G. Song, "A multidelay-and-sum imaging algorithm for damage detection using piezoceramic transducers," Journal of Intelligent Material Systems and Structures, vol. 28, no. 9, pp. 1150-1159, 2017.

[30] W. Gao, L. Huo, H. Li, and G. Song, "An embedded tubular PZT transducer based damage imaging method for two-dimensional concrete structures," IEEE Access, vol. 6, pp. 30100-30109, 2018.

[31] F. Li, H. Peng, and G. Meng, "Quantitative damage image construction in plate structures using a circular pzt array and lamb waves," Sensors and Actuators A: Physical, vol. 214, pp. 66-73, 2014.

[32] Y. Humeida, P. D. Wilcox, M. D. Todd, and B. W. Drinkwater, "A probabilistic approach for the optimisation of ultrasonic array inspection techniques," NDT \& E International, vol. 68, pp. 43-52, 2014.

[33] O. Tofeldt and N. Ryden, "Lamb wave phase velocity imaging of concrete plates with 2D arrays," Journal Nondestructive Evaluation, vol. 37, p. 4, 2018.

[34] Y. Ohara, K. Takahashi, Y. Ino, K. Yamanaka, T. Tsuji, and T. Mihara, "High-selectivity imaging of closed cracks in a coarse-grained stainless steel by nonlinear ultrasonic phased array," NDT \& E International, vol. 91, pp. 139-147, 2017.

[35] J. Cai, L. Shi, S. Yuan, and Z. Shao, "High spatial resolution imaging for structural health monitoring based on virtual time reversal," Smart Materials and Structures, vol. 20, p. 055018, 2011.

[36] R. Zhu, G. L. Huang, and F. G. Yuan, "Fast damage imaging using the time-reversal technique in the frequency-wavenumber domain," Smart Materials Structures, vol. 22, p. 075028, 2013.

[37] N. Mori, S. Biwa, and T. Kusaka, "Damage localization method for plates based on the time reversal of the mode-converted lamb waves," Ultrasonics, vol. 91, p. 19, 2018.

[38] S. M. Parvasi, S. C. M. Ho, Q. Kong, R. Mousavi, and G. Song, "Real time bolt preload monitoring using piezoceramic transducers and time reversal technique-a numerical study with experimental verification," Smart Materials and Structures, vol. 25, Article ID 085015, 2016. 
[39] S. Reyes-Rodríguez, N. Lei, B. Crowgey, L. Udpa, and S. S. Udpa, "Time reversal and microwave techniques for solving inverse problem in non-destructive evaluation," NDT \& E International, vol. 62, pp. 106-114, 2014.

[40] H. Yang, Y. J. Lee, and S. K. Lee, "Impact source localization in plate utilizing multiple signal classification," Proceedings of the Institution of Mechanical Engineers Part C-Journal of Mechanical Engineering, vol. 227, pp. 703-713, 2013.

[41] Y. Zhong, S. Yuan, and L. Qiu, "Multiple damage detection on aircraft composite structures using near-field music algorithm," Sensors and Actuators A: Physical, vol. 214, pp. 234-244, 2014.

[42] Y. Zhong, S. Yuan, and L. Qiu, "Multi-impact source localisation on aircraft composite structure using uniform linear pzt sensors array," Structure and Infrastructure Engineering, vol. 11, no. 3, pp. 310-320, 2015.

[43] C. S. Park, J. W. Kim, S. Cho, and D. Seo, "A high resolution approach for nonlinear sub-harmonic imaging," NDT \& $E$ International, vol. 79, pp. 114-122, 2016.

[44] Y. Wang, S. Yuan, and L. Qiu, "Improved wavelet-based spatial filter of damage imaging method on composite structures," Chinese Journal of Aeronautics, vol. 24, no. 5, pp. 665-672, 2011.

[45] P. Kudela, M. Radzieński, and W. Ostachowicz, "Identification of cracks in thin-walled structures by means of wavenumber filtering," Mechanical Systems and Signal Processing, vol. 50-51, pp. 456-466, 2015.

[46] L. Qiu, B. Liu, S. Yuan, and Z. Su, "Impact imaging of aircraft composite structure based on a model-independent spatialwavenumber filter," Ultrasonics, vol. 64, pp. 10-24, 2016.

[47] L. Qiu, B. Liu, S. Yuan, Z. Su, and Y. Ren, "A scanning spatialwavenumber filter and pzt 2-d cruciform array based on-line damage imaging method of composite structure," Sensors and Actuators A: Physical, vol. 248, pp. 62-72, 2016.

[48] G. Lu, Y. Li, and G. Song, "A delay-and-Boolean-ADD imaging algorithm for damage detection with a small number of piezoceramic transducers," Smart Materials and Structures, vol. 25, no. 9, Article ID 095030, 2016.

[49] L. Yu and Z. Tian, "Guided wave phased array beamforming and imaging in composite plates," Ultrasonics, vol. 68, pp. 43-53, 2016.

[50] Z. Tian, L. Yu, and C. Leckey, "Rapid guided wave delamination detection and quantification in composites using globallocal sensing," Smart Materials and Structures, vol. 25, no. 8, Article ID 085042, 2016.

[51] R. Zhu, G. L. Huang, and F. G. Yuan, "Fast damage imaging using the time-reversal technique in the frequency-wavenumber domain," Smart Materials and Structures, vol. 22, no. 7, Article ID 075028, 2013.

[52] Z. Wu, K. Liu, Y. Wang, and Y. Zheng, "Validation and evaluation of damage identification using probability-based diagnostic imaging on a stiffened composite panel," Journal of Intelligent Material Systems and Structures, vol. 26, no. 16, pp. 2181-2195, 2015.

[53] C. Zhou, Z. Su, and L. Cheng, "Probability-based diagnostic imaging using hybrid features extracted from ultrasonic lamb wave signals," Smart Materials and Structures, vol. 20, no. 12, Article ID 125005, 2011.

[54] C. Zhou, M. Hong, Z. Su, Q. Wang, and L. Cheng, "Evaluation of fatigue cracks using nonlinearities of acousto-ultrasonic waves acquired by an active sensor network," Smart Materials and Structures, vol. 22, no. 1, Article ID 015018, 2013.
[55] D. Gao, Z. Wu, L. Yang, and Y. Zheng, "Guide waves-based multi-damage identification using a local probability-based diagnostic imaging method," Smart Materials and Structures, vol. 25, no. 4, Article ID 045009, 2016.

[56] F. Li, H. Li, J. Qiu, and G. Meng, "Guided wave propagation in H-beam and probability-based damage localization: guided wave propagation in H-beam and damage localization," Structural Control and Health Monitoring, vol. 24, no. 5, p. e1916, 2017.

[57] H. Tanaka and Z. Sharif Khodaei, "Reliability assessment of SHM methodologies for damage detection," Key Engineerig Materials, vol. 713, pp. 244-247, 2016.

[58] V. Giurgiutiu, C. Postolache, and M. Tudose, "Radiation, temperature, and vacuum effects on piezoelectric wafer active sensors," Smart Materials and Structures, vol. 25, no. 3, Article ID 035024, 2016.

[59] Z. Liu, X. Zhong, T. Dong, C. He, and B. Wu, "Delamination detection in composite plates by synthesizing time-reversed lamb waves and a modified damage imaging algorithm based on RAPID," Structural Control and Health Monitoring, vol. 24, no. 5, p. e1919, 2017.

[60] S. Torkamani, S. Roy, M. E. Barkey, E. Sazonov, S. Burkett, and S. Kotru, "A novel damage index for damage identification using guided waves with application in laminated composites," Smart Materials and Structures, vol. 23, Article ID 095015, 2014.

[61] C. S. Kabban, R. Uber, K. Lin, B. Lin, Y. Bhuiyan, and V. Giurgiutiu, "Uncertainty evaluation in the design of structural health monitoring systems for damage detection," Aerospace, vol. 5, p. 45, 2018.

[62] T. Wandowski, P. Malinowski, and W. M. Ostachowicz, "Damage detection with concentrated configurations of piezoelectric transducers," Smart Materials and Structures, vol. 20, Article ID 025002, 2011. 


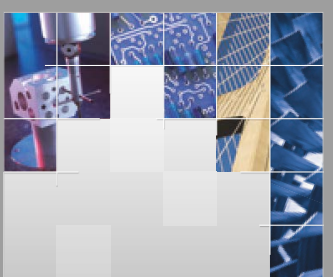

\section{Enfincering}
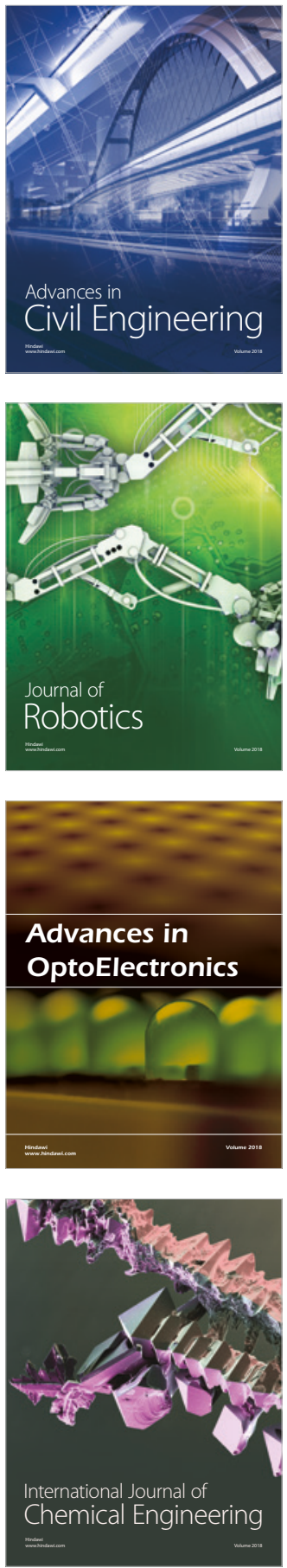

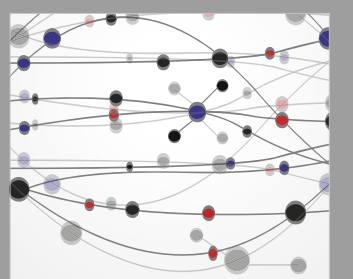

\section{Rotating \\ Machinery}

The Scientific World Journal

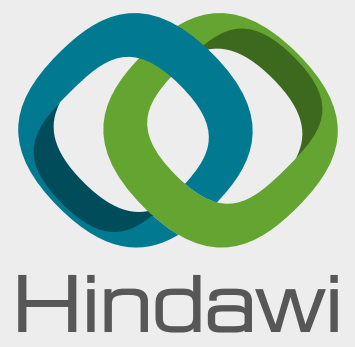

Submit your manuscripts at

www.hindawi.com
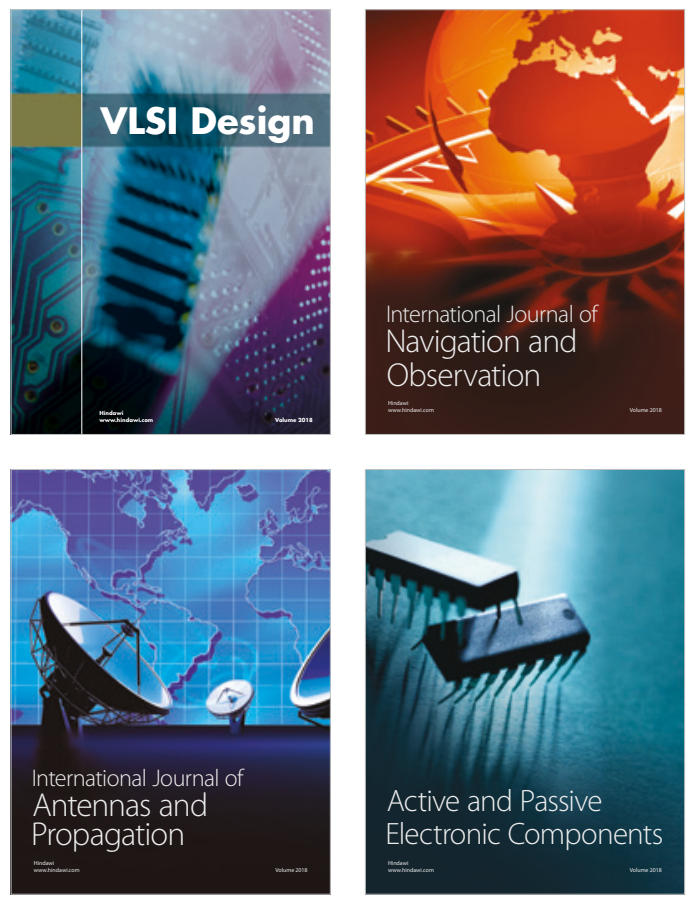
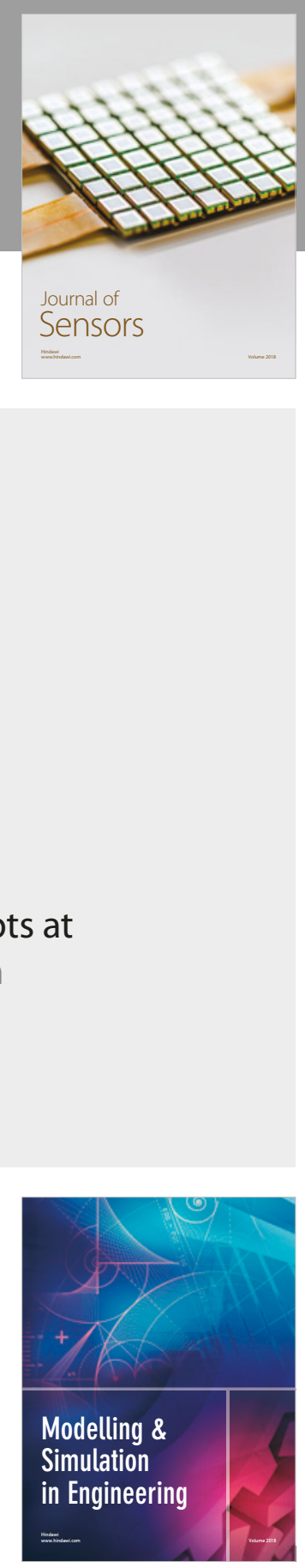

\section{Advances \\ Multimedia}
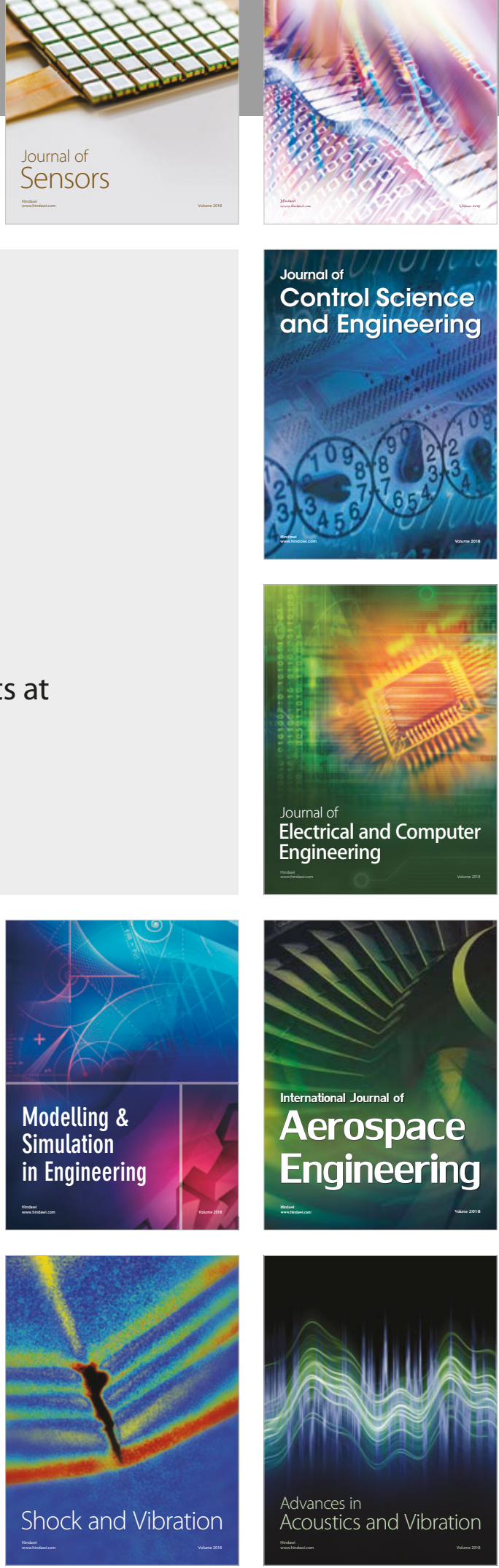